(C) The Author(s) 2019. This is an Open Access article, distributed under the terms of the Creative Commons Attribution-NonCommercial-ShareAlike licence (http://creativecommons.org/licenses/by-nc-sa/4.0/), which permits non-commercial re-use, distribution, and reproduction in any medium, provided the same Creative Commons licence is included and the original work is properly cited. The written permission of Cambridge University Press must be obtained for commercial re-use.

\title{
Air-temperature control on diurnal variations in microseismicity at Laohugou Glacier No. 12, Qilian Mountains
}

\author{
Tao ZHANG, ${ }^{1,2}$ Yuqiao CHEN, ${ }^{1,2}$ Min DING, ${ }^{3}$ Zhongyan SHEN, ${ }^{1,2}$ Yuande YANG, ${ }^{4}$ \\ Qingsheng GUAN ${ }^{1,2,5}$
}

\author{
${ }^{1}$ Key Laboratory of Submarine Geoscience, State Oceanic Administration, Hangzhou 310012, China. \\ E-mail: chenyq_my@163.com; dingmin@pku.edu.cn \\ ${ }^{2}$ Second Institute of Oceanography, State Oceanic Administration, Hangzhou 310012, China \\ ${ }^{3}$ School of Earth and Space Sciences, Peking University, Beijing 100022, China \\ ${ }^{4}$ Chinese Antarctic Center of Surveying and Mapping, Wuhan University, Wuhan 430079, China \\ ${ }^{5}$ School of Geographic and Oceanographic Sciences, Nanjing University, Nanjing 210023, China
}

\begin{abstract}
We conducted a 9-d seismic experiment in October 2015 at Laohugou Glacier No. 12. We identified microseismic signals using the short-term/long-term average trigger algorithm at four stations and classified them as long and short-duration events based on waveform, frequency, duration and magnitude characteristics. Both categories show systematical diurnal trends. The long-duration events are low-frequency tremor-like events that mainly occurred during the daytime with only several events per day. These events lasted tens of seconds to tens of minutes and are likely related to resonance of daytime meltwater. The dominant short-duration events mostly occurred during the night time with a peak occurrence frequency of $\sim 360 \mathrm{~h}^{-1}$. Their short-duration $(<0.2 \mathrm{~s})$, high frequency $(20-100 \mathrm{~Hz})$ and dominance of Rayleigh waves are typical of events for near-surface crack opening. A strong negative correlation between the hourly event number and temperature change rate suggests that the occurrence of night-time events is controlled by the rate of night-time cooling. We estimated the near-surface tensile stress due to thermal contraction at night to be tens of kilopascals, which is enough to induce opening of surface cracks with pre-existing local stress concentrations, although we cannot exclude the effect of refreezing of meltwater produced during the day.
\end{abstract}

KEYWORDS: cracks, glacier geophysics, mountain glaciers, seismicity

\section{INTRODUCTION}

Glacier seismic events were first detected decades ago (Röthlisberg, 1955; Neave and Savage, 1970; OstenWoldenburg, 1990). Numerous investigations (Walter and others, 2008; Winberry and others, 2009; Roux and others, 2010; Carmichael and others, 2012; Walter and others, 2012; Zoet and others, 2012) on glacier seismology have been conducted after the pioneering glacier earthquake study by Ekström and others (2003). Seismic observations of glaciers provide unprecedented high sample rate coverage of glacier dynamic processes (Podolskiy and Walter, 2016). The creation and propagation of surface crevasses is the most prominent sources of glacier seismicity. This seismicity of surface cracks can constrain the strain and stress variations in glaciers and provide insights into the glacier response to environmental changes.

Surface crack seismicity could be induced by temperature variations and/or meltwater. For marine-terminating glaciers, this type of seismicity can also be caused by ocean tides (Barruol and others, 2013; Podolskiy and others, 2016). Most recent studies focused on the effects of meltwater on glacier seismicity, especially on deep and basal icequakes (Walter and others, 2008, 2013; Dalban Canassy and others, 2013). In contrast, studies on the relationship between glacier seismicity and temperature fluctuation are relatively rare, although thermal cracking is considered to be an important mechanism of surface seismicity at cold and dry glaciers when meltwater is limited (Carmichael and others, 2012; Podolskiy and others, 2018). In this study, we focus on the ability of air temperature fluctuations to induce surface crack opening and night-time microseismicity (i.e. short-duration events).

We conducted a 9-d passive seismic experiment on a high-altitude valley (continental) glacier, Laohugou Glacier No. 12 (LGNT), in the Qilian Mountains to the northeast of Tibet in October 2015, when the diurnal air temperature fluctuations are large $\left(>10^{\circ} \mathrm{C}\right)$ but the precipitation $(<20 \mathrm{~mm}$ per month) and meltwater is limited. We identified two types of seismic events from the seismic data and analyzed their temporal distribution, magnitudes, duration and frequency characteristics. We further analyzed the relationship between seismic event occurrence and air temperature and meltwater production. Finally, we discussed the possible sources for the seismic events and quantify the tensile stress due to nighttime thermal contraction. The thermal stress is found to be sufficient large to induce surface crack opening that is responsible for short-duration events.

\section{REGIONAL SETTING AND INSTRUMENTATION}

As the largest glacier in the Qilian Mountains, the LGNT is $9.85 \mathrm{~km}$ long and covers an area of $20.4 \mathrm{~km}^{2}$ (Du and others, 2008; Fig. 1). The LGNT consists of two tributaries and extends from 4260 to 5481 m elevation. The LGNT is a 

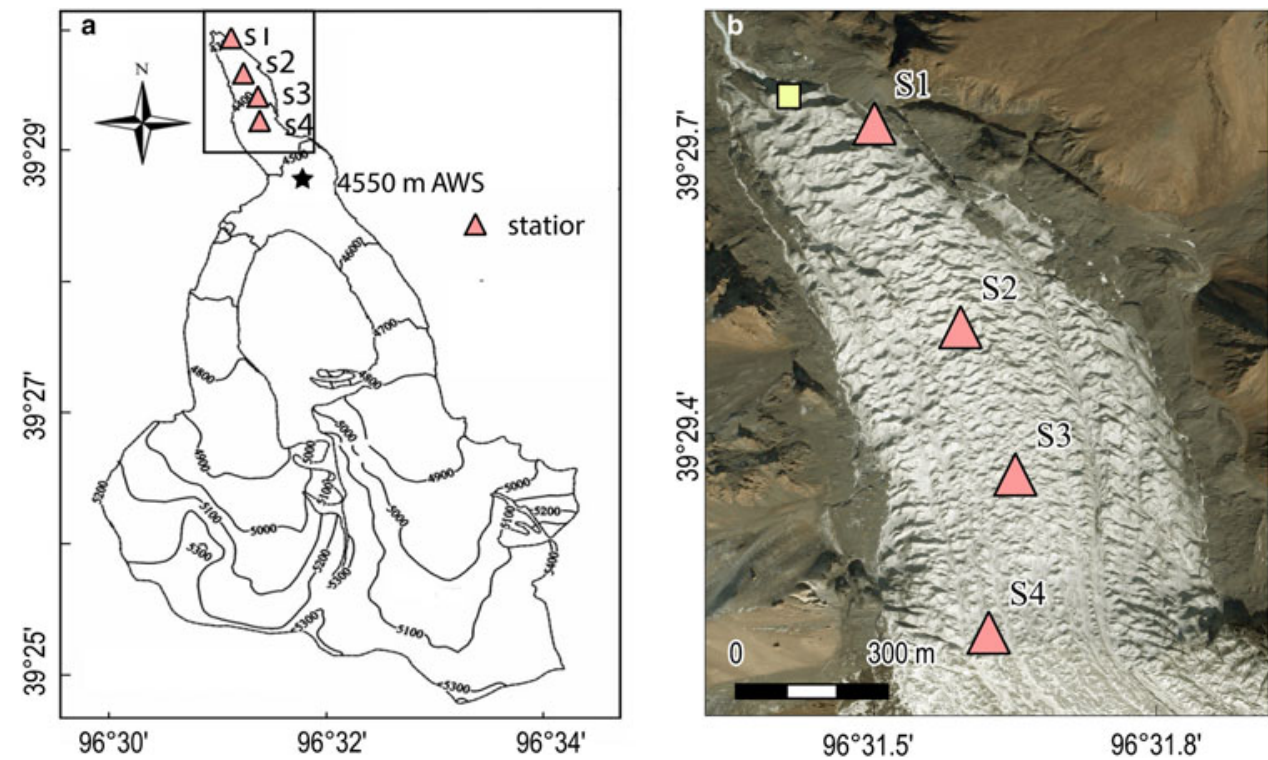

Fig. 1. (a) Contour map of Laohugou Glacier No. 12 with a contour interval of $100 \mathrm{~m}$ (from Liu and others, 2011). The position of the AWS is indicated by a star, and the locations of seismometers S1-S4 by triangles. (b) Enlarged satellite image (DigitalGlobe imagery taken on 9 April 2013, retrieved from http://goto.arcgisonline.com/maps/World_Imagery) of our survey area (black box in a), as well as seismometer locations. The location of our observed moulin is roughly indicated by a yellow square. Note that the station S1 is deployed near the margin of the LGNT.

typical valley glacier in its climate and physical characteristics. Precipitation in this area is mainly affected by westerly winds all year round. The annual precipitation was $310 \mathrm{~mm}$ during 1960-2006 (Qin and others, 2015), with rainfall mainly concentrated between May and September (Liu and others, 2011). In October of 2009, the monthly precipitation was $<20 \mathrm{~mm}$ (Sun and others, 2013). The annual air temperature was $-13.2^{\circ} \mathrm{C}$ during $1957-2013$ (Qin and others, 2014) at $5040 \mathrm{~m}$ elevation. The monthly mean air temperature in October of 2009 was $\sim-11.2^{\circ} \mathrm{C}$ (Sun and others, 2011). In October, the incoming shortwave radiation had an average value of $210.3 \mathrm{~W} \mathrm{~m}^{-2}$ and was up to $676 \mathrm{~W} \mathrm{~m}^{-2}$ at noon time (Sun and others, 2013). The ice thickness along a transversal line at an elevation of $4458 \mathrm{~m}$ (close to our seismic station S4) was 56-128 m as revealed by a ground-penetration radar investigation in the ablation period (July to August) of 2009 and 2014 (Wang and others, 2016).

Our seismic experiment was conducted on the LGNT from 12:30 China Standard Time (CST) of 5 October through 10:16 CST of 14 October 2015. All the records are time-stamped by CST, which is $8 \mathrm{~h}$ ahead of UTC time. We deployed four EPS-1 digital seismometers roughly along the glacier centerline near the terminus of the LGNT at an altitude range of $\sim 4300$ to $4450 \mathrm{~m}$ (Fig. 1), where the averaged surface velocity was $\sim 2.5 \mathrm{~cm} \mathrm{~d}^{-1}\left(\sim 9 \mathrm{~m} \mathrm{a}^{-1}\right)$ in 2008-2009 (Liu and others, 2011). The seismometers were partially buried in the ice in a relatively flat area (without protection cover) and deployed with a spacing of 300-450 m. We checked and maintained the seismometers on a daily basis to ensure the instruments remained level and worked properly. EPS-1 is a cylinder-shaped portable digital seismometer with a radius of $70 \mathrm{~mm}$ and a height of $170 \mathrm{~mm}$. It is a three-component seismometer accompanied with a built-in 24 bit data logger, a data storage unit, and a battery to work continuously for $20 \mathrm{~d}$. The instrument response is flat from 5 to $200 \mathrm{~Hz}$. The output data have a sample rate of $250 \mathrm{~Hz}$ (see http://www.cgif.com.cn/displayproduct. html?prolD=2531321\&ptid=196458 for instrument details).
EPS-1 also includes an internal clock, an electronic compass, and a GPS. The electronic compass was used to record the azimuth and angles, while the GPS provided the initial time and position information. Accompanying position measurements were conducted by a geodetic group from Wuhan University at stations S2 and S3 with Leica GS10 GNSS (Global Navigation Satellite System). The Leica GS10 GNSS has a static horizontal accuracy of $3 \mathrm{~mm}+0.5$ ppm and a static vertical accuracy of $6 \mathrm{~mm}+0.5 \mathrm{ppm}$.

An automatic weather station (AWS) was deployed on the LGNT at 4550 m elevation to measure the air temperature at $1.5 \mathrm{~m}$ above the glacier surface (Sun and others, 2013, 2014; Fig. 1). The AWS was installed on a relatively flat area of the glacier surface using a steel tripod. The temperature sensor has a measurement range of -40 to $60^{\circ} \mathrm{C}$ and an accuracy of $\pm 0.2^{\circ} \mathrm{C}$. The sample rate of the AWS was $0.1 \mathrm{~Hz}$, while the output data were moving averages for every $30 \mathrm{~min}$ (Fig. 6a). The AWS also measures humidity, air pressure, and radiation, as well as wind speed and direction (Fig. 6b).

\section{DATA PROCESSING AND SEISMIC EVENT DETECTION}

To detect seismic events, we applied a classic short-term/ long-term average trigger algorithm (STA/LTA) to the observed vertical component of the seismograms using SEIZMO codes (Euler G: Project SEIZMO, available at: http://epsc.wustl.edu/ ggeuler/codes/m/seizmo/). The method was proposed by Stevenson (1976) and is widely used in the identification of cryoseismic events (Bassis and others, 2007; Walter and others, 2008; Roux and others, 2010; Carmichael and others, 2012; Barruol and others, 2013; Röösli and others, 2014; Köhler and others, 2015). The STA/LTA method uses short and long-term moving windows to localize the seismogram and calculate the corresponding squared amplitudes in the two windows (Trnkoczy, 2012). Once the ratio of the squared amplitudes in the two windows (i.e. $R$ value) exceeds a user-defined trigger 

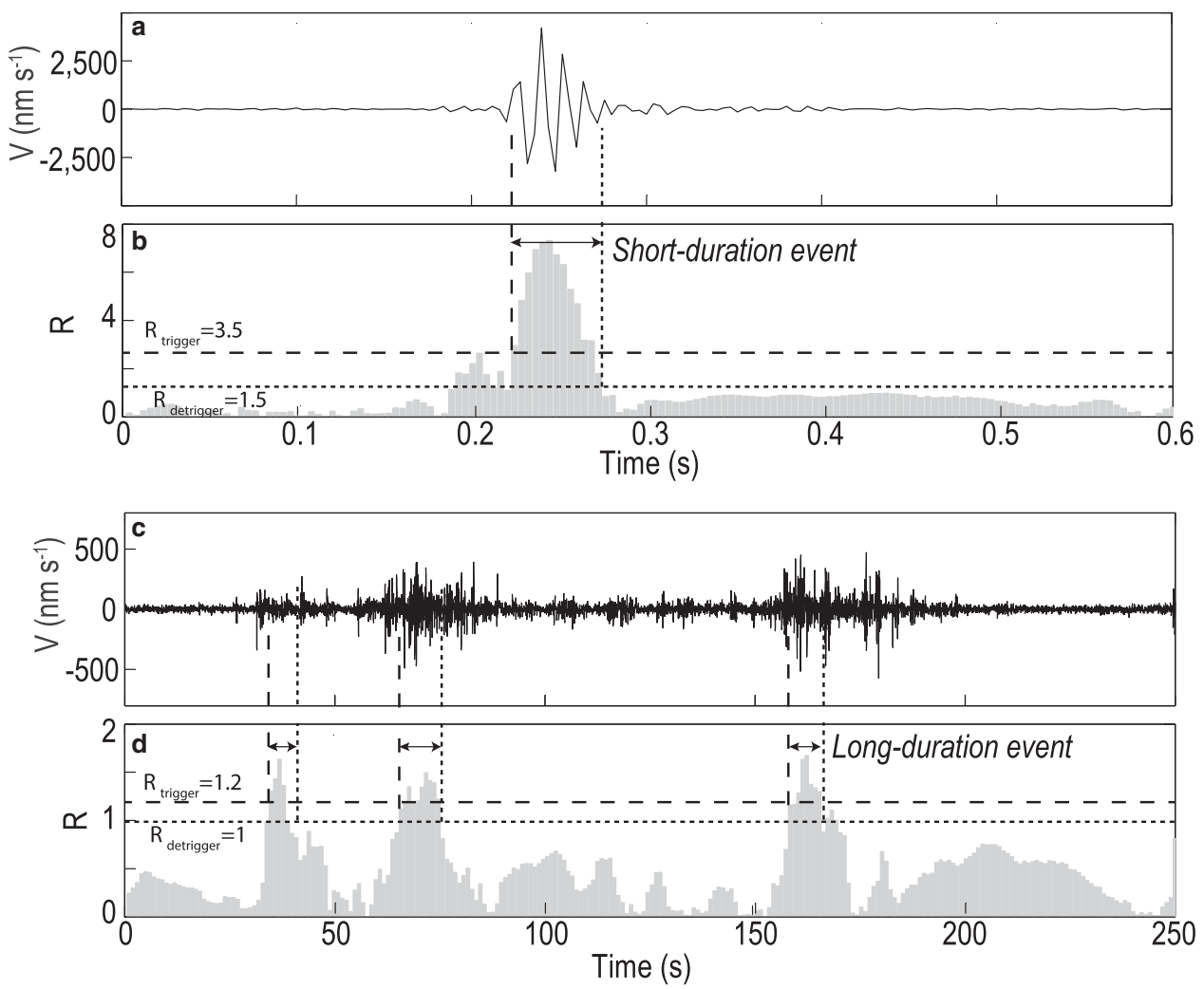

Fig. 2. Typical vertical component of seismograms and STA/LTA ratios for $(a, b)$ a short-duration event starting at 10:20:21 China Standard Time (CST), 9 October, recorded at S1, and (c, d) a long-duration events starting at 13:25:11 CST, 6 October, recorded at S2. The STA/LTA trigger parameters are listed in Table 1.

threshold $R_{\text {trigger, }}$ the trigger is turned on until the $R$ value again falls below a user-defined detrigger threshold $R_{\text {detrigger (Fig. 2). }}$

According to the amplitudes and durations, the identified seismic events were classified into long and short-duration events (Fig. 2). We chose parameters (Table 1) for the STA/ LTA method based on visual inspection and manual picking of a 1-h data subset from station S1. We used a trigger threshold level $R_{\text {trigger }}$ of 3.5 and detrigger threshold level $R_{\text {detrigger }}$ of 1.5 to detect the short-duration events. The STA and LTA time windows were 0.02 and $0.2 \mathrm{~s}$, respectively. The trigger and detrigger thresholds for shortduration events are close to previous studies (Walter and others, 2008; Carmichael and others, 2012; Röösli and others, 2014), but our STA and LTA time windows are one tenth of previously used values of $0.2-1$ and $2-10 \mathrm{~s}$. We chose the shorter time windows to detect all the visible velocity changes in the seismograms, which would be missed if a longer time window was applied.

For the short-duration events, we tested the sensitivity of our results to the trigger threshold and time window (Fig. 3). The event counts detected with different trigger threshold $R_{\text {trigger }}$ values show similar diurnal cycles, although the numbers of seismic events identified with $R_{\text {trigger }}$ values of 3 and 4 are 134 and $76 \%$, respectively, of the total number with an $R_{\text {trigger }}$ value of 3.5 (Fig. 3a). Using a STA time window of $0.2 \mathrm{~s}$ and a LTA time window of $5 \mathrm{~s}$ (from Barruol and others, 2013), we found that the number of detected short-duration events decreases to $\sim 29 \%$ of previous values with shorter time windows (Fig. 3b). However, the diurnal variations still hold. In the following analysis, we focused on the temporal pattern of short-duration events and note that the number of detected seismic events depends on STA/LTA time windows and trigger (and detrigger) thresholds.

\section{OBSERVATIONS}

\section{Meteorological conditions}

The air temperature obtained from the AWS station at $4550 \mathrm{~km}$ elevation shows a clear diurnal cycle during the survey period (Fig. 6a). The average air temperature over $9 \mathrm{~d}$ was about $-5.2^{\circ} \mathrm{C}$, with a maximum temperature of $1.4^{\circ} \mathrm{C}$ and a minimum temperature of $-8.1^{\circ} \mathrm{C}$. The highest and lowest temperatures appeared at 13 CST and 7 CST, respectively. The temperatures rose rapidly from 9 CST to 12 noon and dropped slowly from 17 CST to 7 CST the following morning. The local sunrise and sunset during our survey period was $\sim 7: 30$ CST and $\sim 19$ CST, respectively. The wind speed (Fig. 6b) and glacier surface humidity also show diurnal cycles, which results in a deviation of the ice surface temperature from the air temperature based on glacier surface energy budget considerations (Sun and others, 2014). However, comparison between air and ice surface temperature measurements (Sun and others, 2014) in June-September 2011 showed a similar diurnal pattern and same daily hours with maximum and minimum temperatures, although the glacier surface temperature was systematically lower than the air temperature by $2-4^{\circ} \mathrm{C}$. In this study, we use the air temperature as a proxy for the air surface temperature, due to the lack of direct ice surface temperature measurements during our survey period. 


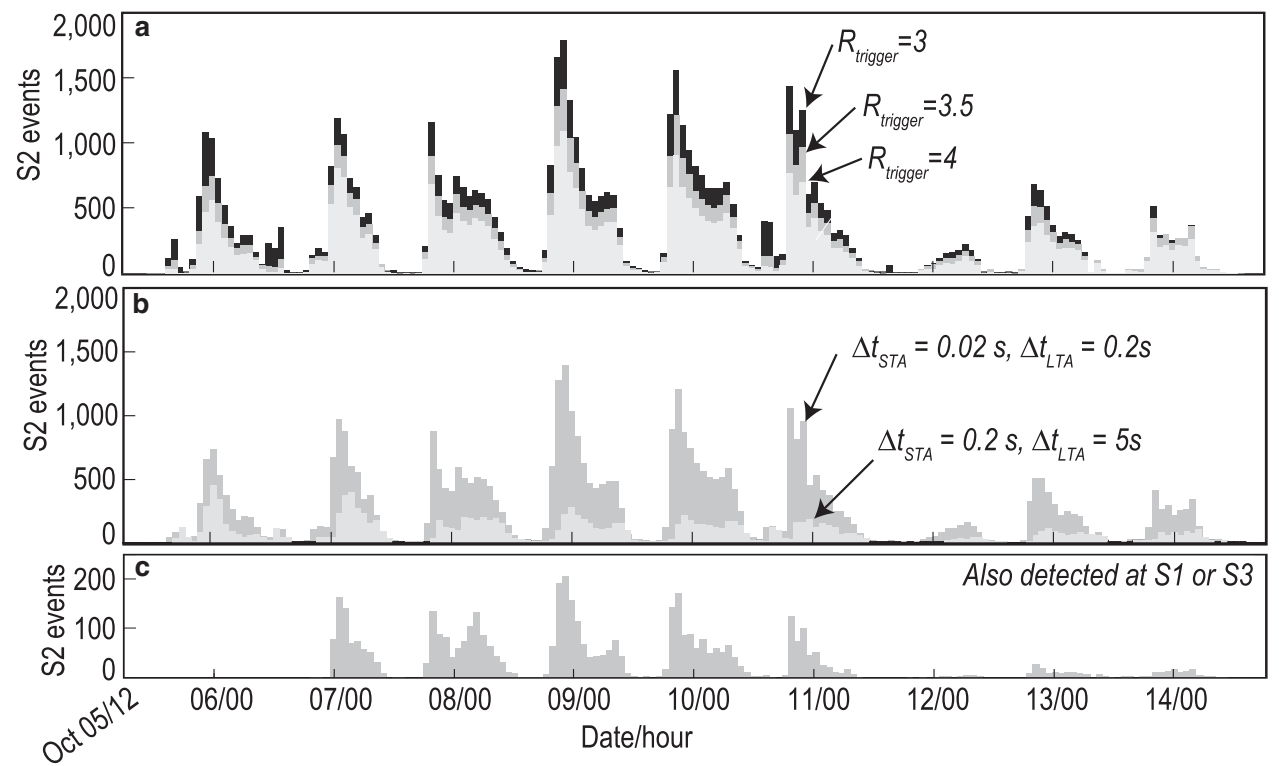

Fig. 3. Sensitivity of hourly short-duration event counts at S2 to (a) trigger threshold $R_{\text {trigger }}$ (b) STA/LTA window widths and (c) application of waveform association analysis (Fig. 8). Date and hour are in CST.
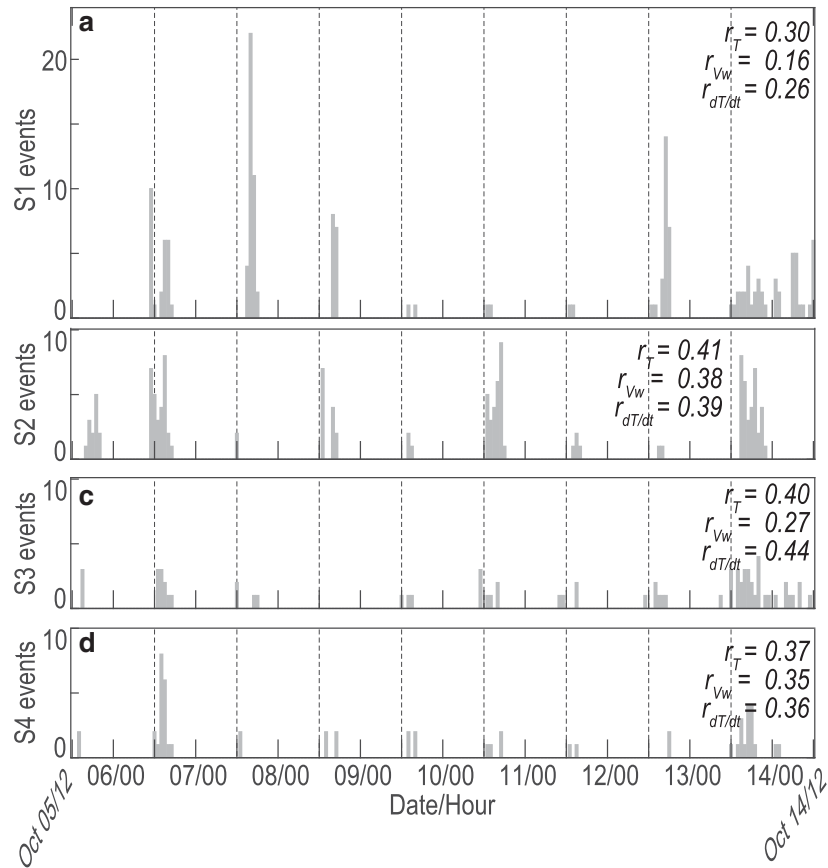

Fig. 4. Counts of detected long-duration events per hour for stations S1-S4. The correlation coefficients between the hourly event counts and air temperature (Fig. 6a), wind speed (Fig. 6b) and temperature change rate (Fig. 6c) are listed in the top right corners. Date and hour are in CST.

On 11 October 2015, snowfall lasted from 15 CST to 7 CST the following morning (Fig. 6). Approximately $5 \mathrm{~cm}$ of snow covered the LGNT until the end of our observation. We did not collect hydrological data, but note that no sound of water flow was heard in the field and the downstream riverbed was dry during the observation period. We only observed limited surface melting in the daytime close to the glacier fringes. Although the air temperature was mostly below $0^{\circ} \mathrm{C}$ during our observation period, the local solar radiation, wind, and cloud may lead to slight surface melting at noon. In addition, we found an ice moulin of $\sim 5 \mathrm{~m}$ wide at a distance of $\sim 100 \mathrm{~m}$ to the northwest of our seismic station S1 (Fig. 1b), close to the glacier terminus. The ice moulin was dry during our survey period.

\section{Long-duration events}

We detected a total of 158, 129, 65 and 49 long-duration events for the four stations in the 9 survey days (Fig. 4) based on the parameters in Table 1. Most of the longduration events occurred between 12 noon and 18 CST in the daytime, when the air temperature ranged from -3 to $-1{ }^{\circ} \mathrm{C}$. On the last day of our survey (i.e. 11 October), the long-duration events were also identified at night. The amplitudes of long-duration events are relatively low (Figs 2 and 5). Their waveforms lack impulsive onsets, and distinct body or surface wave arrivals. The duration of the long-duration events is tens of seconds to tens of minutes. We selected three representative long-duration events for detailed spectral analysis (Fig. 5), which shows a dominant frequency below $20 \mathrm{~Hz}$. The long-duration events may also be associated with a higher secondary resonance frequency, e.g. $80 \mathrm{~Hz}$ in Figure $5 \mathrm{a}$ and $40 \mathrm{~Hz}$ in Figure 5b. Spectrograms for these two selected events also clearly show a temporal evolution of the resonance frequency (bottom panels of Figs $5 \mathrm{a}$ and $\mathrm{b})$.

\section{Short-duration events}

We detected 4514 short-duration events per day on average for an individual station (Fig. 6), which is hundreds of times more than the number of detected long-duration events. At each seismic station, the number of short-duration events was similar in the first $6 \mathrm{~d}$ of observation. After a snowfall, the daily number of short-duration events in the last $3 \mathrm{~d}$ of observation decreased to $\sim$ one-fifth of that during the first 6 d. Most (95\%) of the short duration events lasted for 0.04$0.25 \mathrm{~s}$ (Fig. 7a). The waveforms of the short-duration events are dominated by Rayleigh waves without visible P- or Sphase arrivals (Fig. 2a). The dominant frequencies of the events range widely from 20 to $100 \mathrm{~Hz}$, with local peaks at 

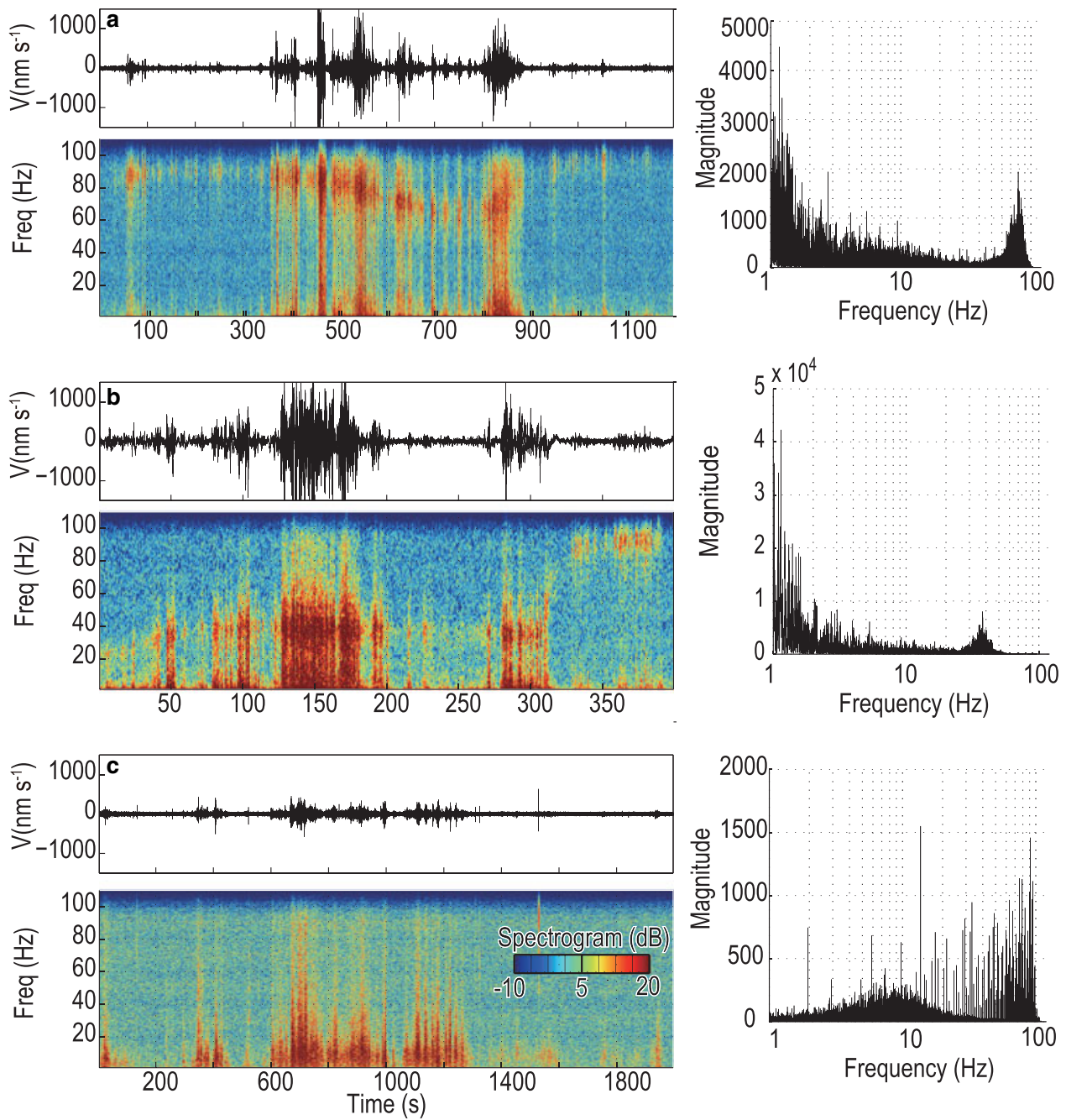

Fig. 5. Waveforms (top), spectrograms (bottom) and power spectra (right) for three representative long-duration events with starting times of (a) 11:35:11 CST, (b) 12:10:05 CST and (c) 15:14:04 CST on 6 October, detected at the seismic stations S2, S2, and S4, respectively.

30, 50, 75 and $90 \mathrm{~Hz}$ (Fig. 7b). The event counts increase with frequency, and the maximum frequency is close to the Nyquist frequency of $125 \mathrm{~Hz}$.

The dominance of Rayleigh waves is consistent with the waveforms observed in previous studies (Neave and Savage, 1970; Walter and others, 2009; Dalban Canassy and others, 2013; Röösli and others, 2014; Carmichael and others, 2015), in which the source mechanism has been attributed to surface tensile cracks within the surface crevasse zone (top $\sim 20 \mathrm{~m}$ of the glacier). However, our detected events are shorter in duration, higher in frequency and more frequent than reported from other glaciers. This is mainly due to our chosen shorter time windows for the STA/LTA detector, and less significantly due to repeatedly counting seismic events at multiple stations. To reduce duplicate counts, we performed a waveform association analysis, similar to Carmichael and others (2015). This analysis identifies the events detected at different stations within a time interval less than the expected travel time across the network as the same event. However, due to the difficulty of locating the small short-duration events in this study, we can only use the maximum travel time between two stations, which was calculated as the distance between two stations divided by an assumed Rayleigh wave velocity of $1660 \mathrm{~m} \mathrm{~s}^{-1}$ (Mikesell and others, 2012). The waveform association analysis thus provides maximum estimates of the event counts that are recorded at two, three and four stations simultaneously, which are $\sim 23,4$ and $0.2 \%$ of the total event counts recorded at one station (Fig. 8). The events recorded at multiple stations are expected to be larger in magnitude, and thus the rapid reduction in the event counts is in line with our expectation of an exponential decrease of event counts with magnitude. We plotted the hourly event counts detected simultaneously at two stations in Figure 3c. The diurnal cycle is clearly visible and thus is a robust observation.

The diurnal cycle is the most significant temporal pattern of short-duration events (Figs 6 and 9). Nearly all the shortduration events occurred between 19 CST and 9 CST the following morning, with peak event counts at 20-23 CST. The starting and ending times of the daily burst of seismic events, 19 CST and 9 CST, were confirmed by low $p$-values in paired $t$-tests (Fig. $9 \mathrm{~d}$ ). These starting and ending times have an uncertainty of $1 \mathrm{~h}$, as it is based on hourly seismic event counts. After the starting time of 19 CST, the event counts rapidly increased to the maximum occurrence frequency of $363 \mathrm{~h}^{-1}$ at 20 CST (Fig. 9c). The event counts then gradually decreased at night till $112 \mathrm{~h}^{-1}$ at 9 CST the next morning. In the daytime, the event frequency is $<40 \mathrm{~h}^{-1}$.

The counts of short-duration events (Figs 6d-g and 9c) are strongly and negatively correlated with the temperature fluctuation (Figs $6 a$ and 9a) with correlation coefficients of -0.43 to -0.32 for the four seismic stations. Most short-duration 


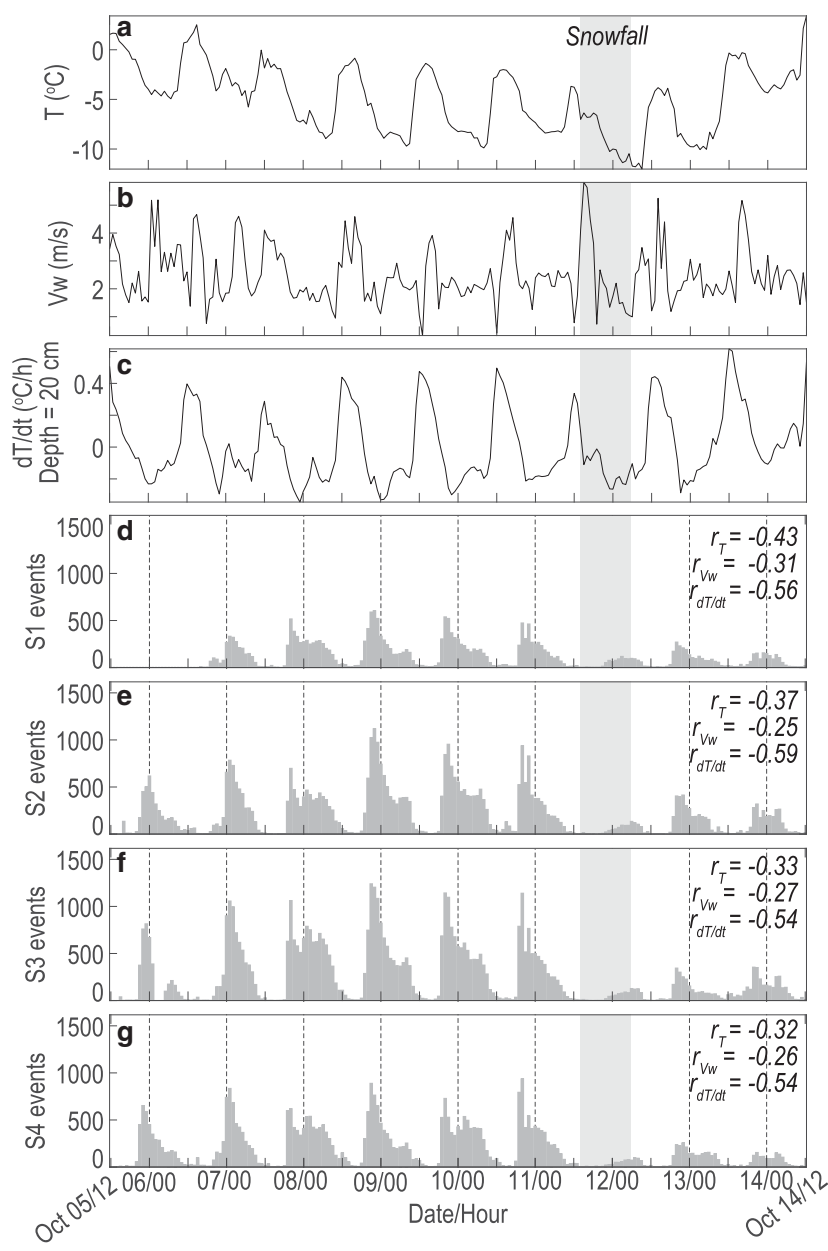

Fig. 6. (a) Air temperature, (b) wind speed, (c) calculated temperature change rate at a depth of $20 \mathrm{~cm}$ and $(\mathrm{d}-\mathrm{g})$ hourly short-duration events detected at S1-S4. The correlation coefficients between short-duration events and air temperature, wind speed and temperature change rate are listed in the top right corners. Date and hour are in CST. We did not deploy station S1 on the first day.

events occur when the air temperature decreases from $-4^{\circ} \mathrm{C}$ at $19 \mathrm{CST}$ to $-7^{\circ} \mathrm{C}$ at $9 \mathrm{CST}$ the next morning. The occurrences of short-duration events are also negatively correlated with wind speed (Fig. 6b). It has been suggested that wind or water-generated tremor noise in the daytime may reduce the detectability of seismic events (Röösli and others, 2014). We applied a highpass filter at $20 \mathrm{~Hz}$ to suppress the low-frequency wind or water-generated noise. Results (Fig. 10b) show that the short-duration events are still concentrated at night due to their high frequency and amplitude. Therefore, the low detection of short-duration events in the daytime may not due to increased tremor noise. Instead, a source mechanism preferentially operating at night is necessary to explain the occurrence of short-duration events.

\section{Local magnitude of short-duration events}

To characterize the energy/amplitude of the short-duration events, we calculated the local magnitudes $\left(M_{1}\right)$ using the method of Richter (1935):

$$
M_{\mathrm{l}}=\log \left(\frac{A}{A_{0}}\right)
$$

Table 1. Parameters for seismic event identification for the STA/LTA method

\begin{tabular}{lll}
\hline & $\begin{array}{c}\text { Short-duration } \\
\text { events }\end{array}$ & $\begin{array}{c}\text { Long-duration } \\
\text { events }\end{array}$ \\
\hline STA window width $\Delta t_{\mathrm{STA}}(\mathrm{s})$ & 0.02 & 4 \\
LTA window width $\Delta t_{\mathrm{LTA}}(\mathrm{s})$ & 0.2 & 36 \\
STA/LTA trigger threshold $R_{\text {trigger }}$ & 3.5 & 1.2 \\
STA/LTA detrigger threshold & 1.5 & 1 \\
$\quad R_{\text {detrigger }}$ & & \\
$\begin{array}{l}\text { Minimum interval between two } \\
\text { events }(\mathrm{s})\end{array}$ & 0.02 & 5 \\
& &
\end{tabular}

where the parameter $A$ is the maximum amplitude of displacement, and $A_{0}$ is a correction factor defined by a reference zero magnitude earthquake that generates a displacement of $1 \mu \mathrm{m}$ at a $100 \mathrm{~km}$ distance. We adopt the empirical $A_{0}$ value provided by Richter (1958), which was originally estimated for southern California but is also used worldwide (Roux and others, 2008).

Our estimated $M_{1}$ of the short-duration events range from -2 to 0.5 (Fig 7c). Following Podolskiy and others (2016) (citing Barruol and others, 2013), we found that the magnitude distribution fits a Gutenberg-Richter distribution (Gutenberg and Richter, 1944): $\log N=a-b \times M_{1}$. We estimated the parameters $a$ and $b$ to be $3.75 \pm 0.02$ and $0.99 \pm$ 0.01 , respectively (Fig. $7 d$ ). Our estimated $b$ value is close to 1 , consistent with previous estimated $b$-value estimates for surface crack events (Podolskiy and Walter, 2016 and references therein). Our fitting to the Gutenberg-Richter distribution implies a magnitude of completeness of -1.2 (Fig. 7d), below which a large portion of weaker events were not detected. We also grouped the detected shortduration events on an hourly basis to test the evolution of $b$ value. However, no clear temporal evolution trend of the $b$ value was found.

\section{SEISMIC SOURCE FOR SHORT-DURATION EVENTS}

\section{Thermally induced opening of surface cracks}

Most of our detected short-duration events are expected to occur near the surface (maximum 20 m depth) due to the dominance of Rayleigh waves (Walter and others, 2009; Röösli and others, 2014; Podolskiy and Walter, 2016). In contrast, seismograms of deep or basal events have relatively large P-wave amplitudes without the presence of Rayleigh waves (Deichmann and others, 2000; Dalban Canassy and others, 2013). Although it is impossible to determine the fracture mode (shear or tensile) of the seismic events due to the lack of $\mathrm{P}$ wave polarity observations, we suggest that the surface events are more likely to be tensile cracks as the tensile strength is much less than the shear strength (Schulson, 2002). Additionally, the tensile strength can be easily overcome at night due to thermal contraction (next paragraph). When local stress near the defects or crack tips exceeds the fracture toughness according to the fracture mechanic considerations (van der Veen, 1998, 1999), the formation or propagation of surface cracks can be recorded as seismic events.

The concentration of surface crack opening at night could be induced by thermal stress or refreezing meltwater. Daytime meltwater may accumulate in surface crevasses; 

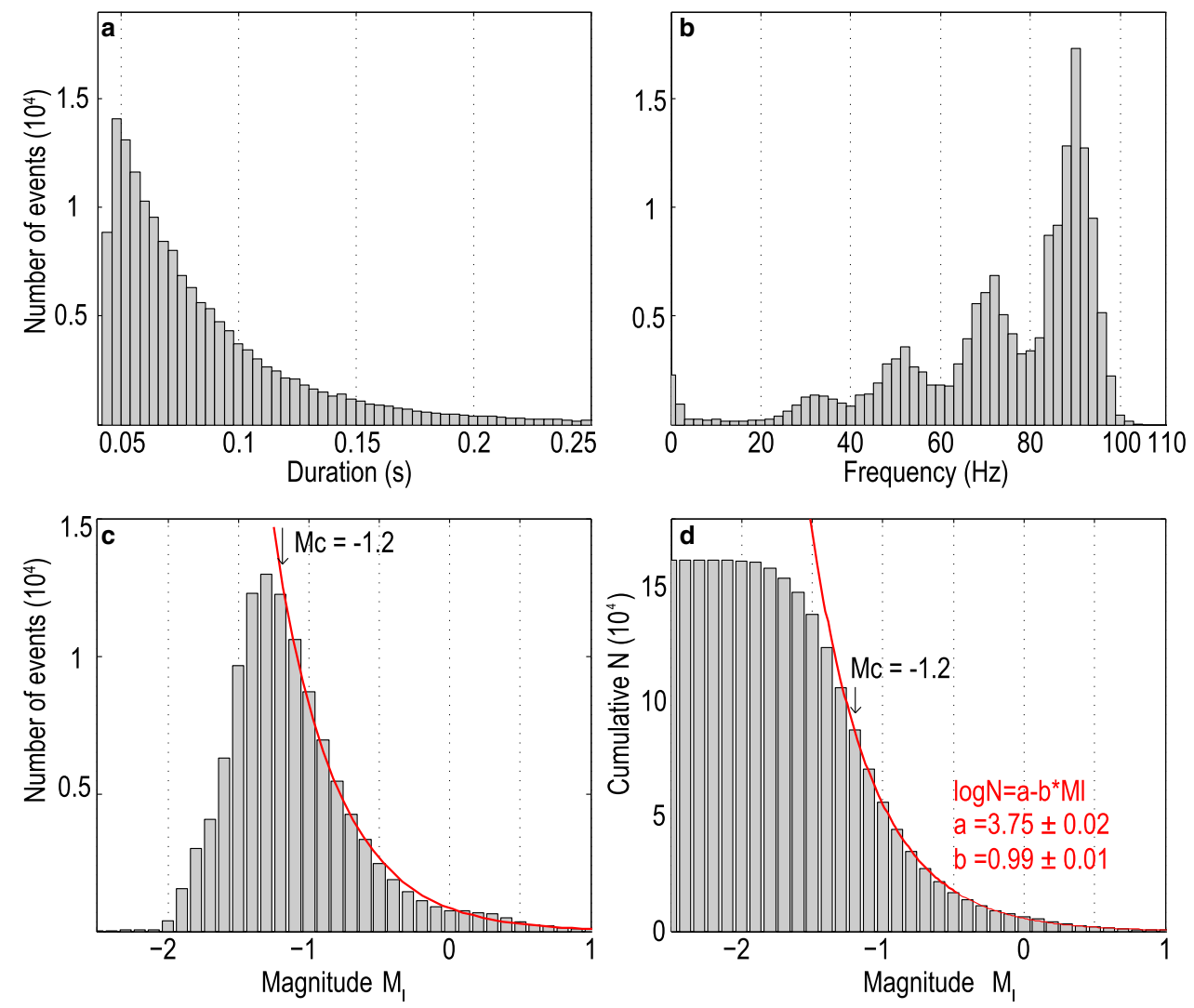

Fig. 7. Histograms of (a) duration, (b) frequency and (c) local magnitude for the short-duration seismic events. (d) Corresponding cumulative distribution of the seismic magnitude in (c). Red curves correspond to the best-fit to the Gutenberg-Richter distribution.

refreezing of meltwater at night can trigger crack initiation and propagation (van der Veen, 2007). An alternative mechanism is that reduced meltwater at night increases effective basal stress and thus induces spatial variations in surface strain (Carmichael and others, 2015). However, the increased basal stress mechanism requires considerable amounts of meltwater at the base of the glacier, which is less likely to occur at LGNT in October.

Although we cannot exclude the effect of meltwater refreezing at night, we found that thermal contraction alone can induce enough tensile stress in the top tens of centimeters to promote tensile crack opening and seismic events (next section). This thermal contraction effect is supported by the significant negative correlation between the counts of short-duration events and the air temperature, and temperature change rate (Fig. 6). A similar negative correlation has been reported at a Himalayan glacier (Podolskiy and others, 2018) and interpreted as having a thermal origin. In addition, the snowfall on the 7th day of our observations is expected to damp heat conduction. The corresponding reduction in the thermal stress can explain the observed decrease in the icequake event number after the snowfall, which further corroborates the causal relationship between the thermal stress and short-duration events.

\section{Thermal stress evolution}

As the temperature decreases, the thermal contraction of the ice exerts tensile stress on the surface ice layer. Once the stress exceeds a threshold value, the opening of surface cracks occurs, which could be recorded as icequakes. To quantify the thermal stress in response to the diurnal temperature fluctuation, we first calculated the propagation of the temperature waves $T(z, t)$ at depth $z$ and time $t$ based on the Fourier equation of heat conduction following Sanderson (1978) and Nishio (1983):

$$
\begin{gathered}
T(z, t)=T_{0}+\sum_{s=1}^{N} T_{s} \exp \left[-z\left(\frac{\omega_{s}}{2 k}\right)^{1 / 2}\right] \\
\cos \left[\omega_{s} t-\phi_{s}-z\left(\frac{\omega_{s}}{2 k}\right)^{1 / 2}\right]
\end{gathered}
$$

where the thermal diffusivity $k$ is assumed to be $1.091 \times$ $10^{-6} \mathrm{~m}^{2} \mathrm{~s}^{-1}$ for a constant ice density of $0.9 \mathrm{~g} \mathrm{~cm}^{-3}$ (Sanderson, 1978). The temperature amplitudes $T_{0}$ and $T_{s}$, frequency $\omega_{s}$ and phase $\phi_{s}$ depend on the Fourier transformation of surface temperature (assuming to be equal to the air temperature): $\quad T(0, t)=T_{0}+\sum_{s=1}^{N} T_{s} \cos \left(\omega_{s} t-\phi_{s}\right)$. The Fourier transformation was computed using the Matlab Fast Fourier transformation codes $\mathrm{fft}$ and ifft, in combination with Fourier coefficient conversion codes complex2real and real2complex (written by Boynton GM for the course of Introduction to Programing for the Behavioral Sciences, Autumn, 2015, University of Washington. Retrieved from http://courses.washington.edu/matlab1/matlab).

The short-duration events mostly occur when the temperature drops at a depth of $20 \mathrm{~cm}$ (i.e. when temperature change rate is negative). The correlation of the short-duration event counts with the temperature change rate at $20 \mathrm{~cm}$ depth (Figs 6c and 9b) is -0.56 to -0.54 for the four seismic stations, which is more significant than the correlation with 


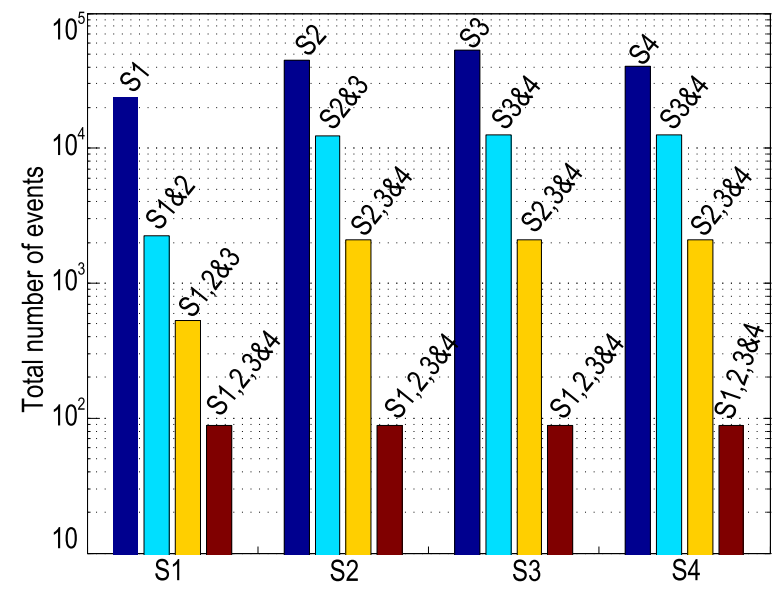

Fig. 8. Estimates of the short-duration event counts after applying waveform association analysis to exclude the potential repeated counts. The events simultaneously recorded at two stations (light blue), three stations (orange), and four stations (red) are $\sim 23,4$ and $0.2 \%$ of the events recorded at one station (blue).

the surface temperature fluctuation. The daily-averaged evolution of the temperature and temperature change rate within the top one meter of the glacier ice clearly shows diurnal variations (Figs 11c1 and d1). Figures 11c2 and d2 show depthdependent temperature and temperature rate profiles at four representative hours. The diurnal temperature cycle only influences the top $1 \mathrm{~m}$ of the glacier, with rapidly decreasing amplitude with depth due to attenuation of temperature waves (black curves in Figs 11c2 and d2).

Sanderson (1978) considered that the surface ice layer cannot move as it is constrained both horizontally and vertically. Internal stress, instead of strain, is thus induced by temperature changes. This thermal stress was calculated by considering the strain rate that would occur if the ice body is free to expand or contract, and then estimating the stress required to reduce the strain rate to zero using Glen's flow law (Glen, 1955):

$$
\dot{\varepsilon}_{i}^{\prime}=C \tau^{n-1} \sigma_{i}^{*},
$$

where $\tau$ is the second invariant of the deviatoric stress tensor $\sigma_{i}^{*}$ and $C$ is the creep parameter. The best estimate for $n$ is 3 based on laboratory experiments and glacial morphologic studies (Sanderson, 1978; Cuffey and Paterson, 2010).

The final formula in Sanderson (1978) to estimate the horizontal principal stresses due to restrained thermal expansion and contraction are as follows:

$$
\begin{gathered}
\sigma_{1}^{*}=\left(\frac{\dot{\varepsilon}^{\prime}{ }_{1}}{C\left(1+a+a^{2}\right)}\right)^{1 / 3}, \\
\sigma_{2}^{*}=a \sigma_{1}^{*},
\end{gathered}
$$

where $\dot{\varepsilon}_{1}^{\prime}=\dot{\varepsilon}_{1}-\alpha((\partial T) /(\partial t))$ and $\dot{\varepsilon}_{2}^{\prime}=\dot{\varepsilon}_{2}-\alpha((\partial T) /(\partial t))$ are the sum of the background strain rates, $\dot{\varepsilon}_{1}$ and $\dot{\varepsilon}_{2}$, minus the thermal strain rate (extension or contraction) if the ice body is unconstrained. $a=\dot{\varepsilon}_{2}^{\prime} / \dot{\varepsilon}_{1}^{\prime}$ is the ratio between the two strain rate components. The expansion coefficient $\alpha$ is assumed to be linearly related to the temperature as $\alpha=5.4 \times 10^{-5}+1.8 \times 10^{-7} T$ (Nishio, 1983) instead of a constant value in Sanderson (1978).

The creep factor $C$ depends on the temperature following an Arrhenius relationship: $C=C_{*} \mathrm{e}^{-(Q / R)\left((1 / T)-\left(1 / T_{*}\right)\right)}$, where $T$
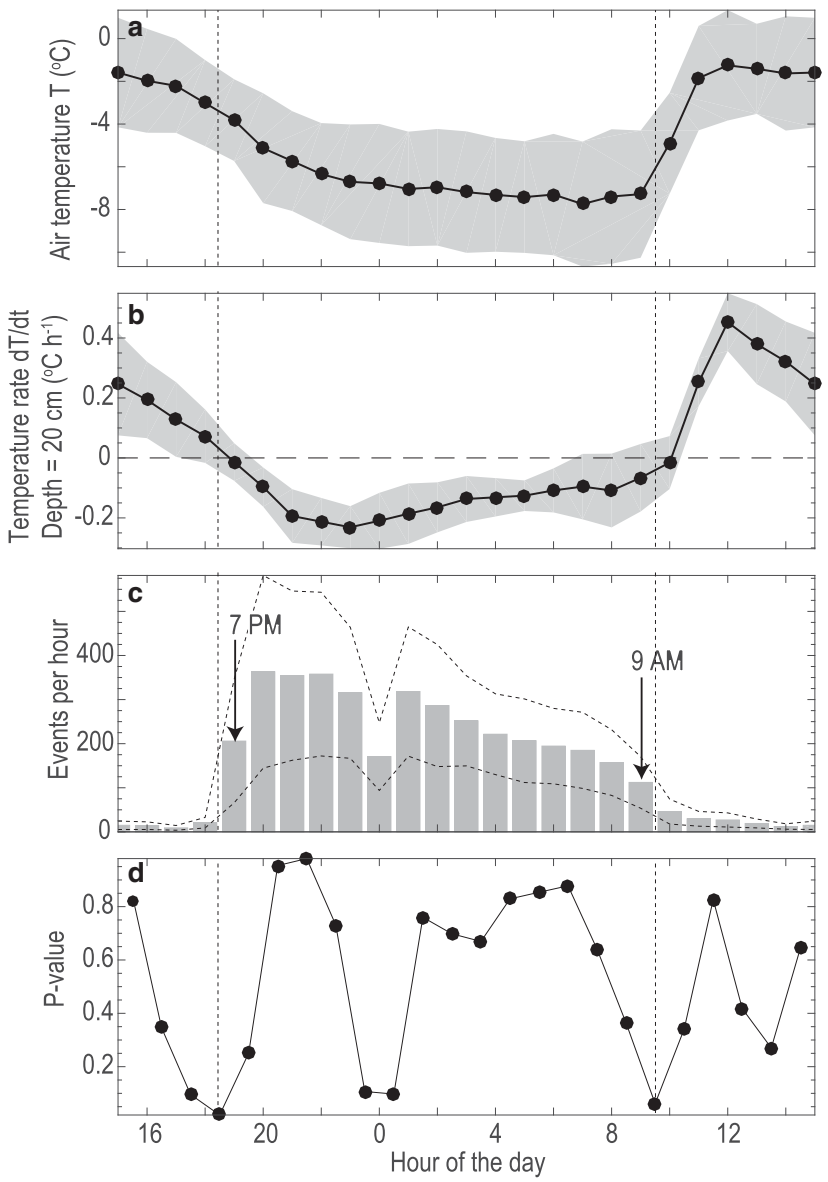

Fig. 9. Nine-day averaged (a) air temperature, (b) temperature change rate at a depth of $20 \mathrm{~cm}$ and (c) counts of short-duration events per hour. (d) Probability values (i.e. $p$-values) of the statistical test (i.e. two-sample $t$-test) for the hypotheses that the neighboring $2 \mathrm{~h}$ have different mean seismic event counts. The notable low $p$-values at 19 CST and 9 CST indicate the initiation and ending hours for the daily burst of the short-duration events. The gray regions and dashed lines indicate the 95\% confidence intervals (i.e. 1.96 times the standard error) for the hourly mean values.

is the variable temperature that depends on both depth and time, and $T_{*}=263 \mathrm{~K}$ is a transition temperature above which ice softening increases. The gas constant $R$ is equal to $8.314 \mathrm{~J} \mathrm{~mol}^{-1} \mathrm{~K}^{-1}$. The parameter values $C_{*}=3.5 \times$ $10^{-25} \mathrm{~Pa}^{-3} \mathrm{~s}^{-1}$ and $Q=1.15 \times 10^{5} \mathrm{~J} \mathrm{~mol}^{-1}$ are based on laboratory experiments and glacial morphologic studies (Cuffey and Paterson, 2010 and reference therein). This $C_{*}$ value is several orders of magnitude larger than the value used by Sanderson (1978), while $Q$ is only slightly larger than Sanderson (1978). This updated $C_{*}$ value incorporates the state-of-the-art lab and field measurements of the glacier creep characteristics, resulting in a lower magnitude of stress in our calculation than Sanderson (1978).

We considered two scenarios for the background strain rate: $\dot{\varepsilon}_{1}=\dot{\varepsilon}_{2}=0$ and $\dot{\varepsilon}_{1}=4 \times 10^{-10} \mathrm{~s}^{-1}$ (i.e. $0.013 \mathrm{a}^{-1}$ ) and $\dot{\varepsilon}_{2}=-4 \times 10^{-10} \mathrm{~s}^{-1}$. The calculated thermal stress $\sigma_{1}^{*}$ has similar diurnal pattern in the top $50 \mathrm{~cm}$ of the glacier (Figs $11 \mathrm{e}-\mathrm{f}$ ), but the latter scenario is associated with an additional extensional stress of $\sim 70 \mathrm{kPa}$ at depth due to the background extensional strain rate (Fig. 11f). Our stress calculation for the first scenario shows that the thermal expansion and contraction of the ice leads to diurnal 


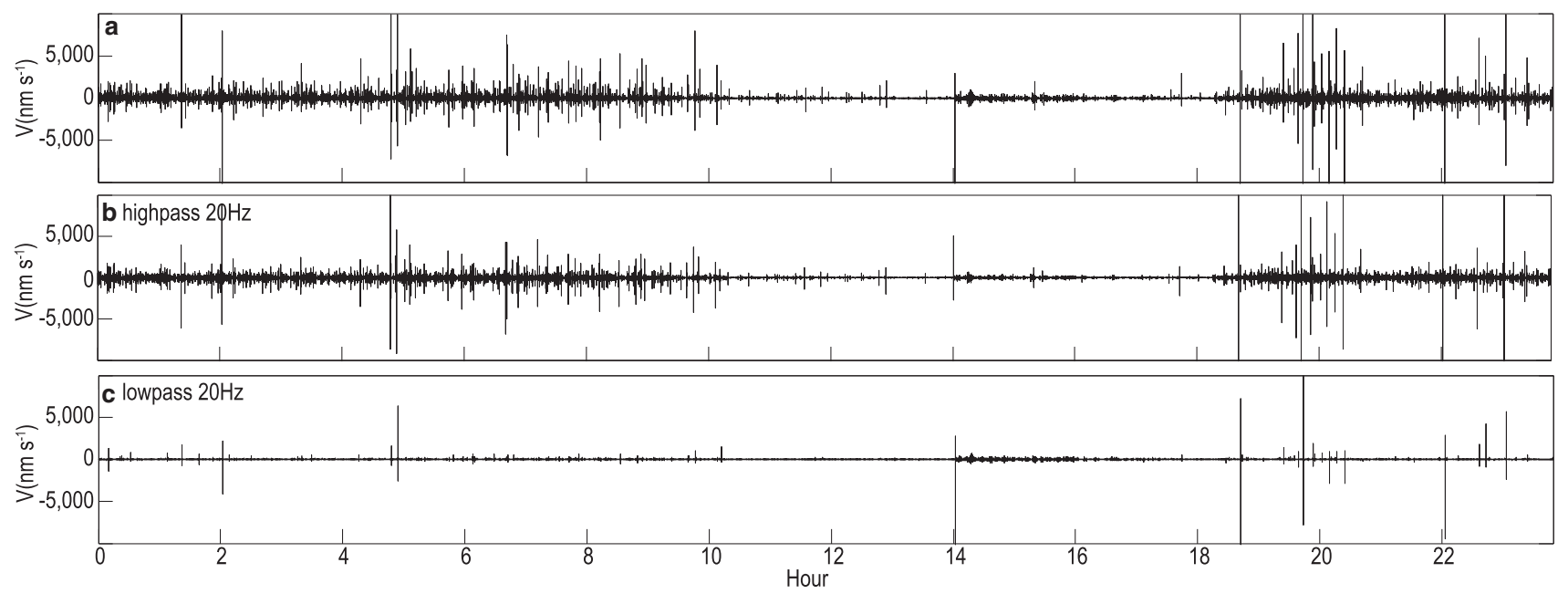

Fig. 10. (a) One-day plot of the seismic records from 10 to 11 October at $S 2$, and filtered seismograms after applying (b) highpass and (c) lowpass filters at $20 \mathrm{~Hz}$.

variations in $\sigma_{1}^{*}$ from compression to tension with a maximum tensile stress of $48-184 \mathrm{kPa}$ in the top $50 \mathrm{~cm}$ (Fig. 11e2). The calculated surface stress becomes tensile after 15 CST as the air temperature starts to decrease (red curves in Fig. 11b). The tensile stress region extends to 20 $\mathrm{cm}$ when the hourly short-duration events notably increase at 19 CST. At this time, the surface tensile stress is $156 \mathrm{kPa}$. After that, the tensile stress region continuously penetrates to greater depth, with reduced amplitude due to depth attenuation of temperature waves. At 8 CST, the air temperature starts to increase and the surface stress becomes compressional. Accordingly, the tensile stress region shrinks. One hour after that, the top $10 \mathrm{~cm}$ becomes compressional in stress. This is also the ending time of the daily burst of short-duration events.

For the latter scenario with background strain rate, we assumed a background compressional strain rate $\dot{\varepsilon}_{2}$ of $-4 \times 10^{-10} \mathrm{~s}^{-1}$. This strain rate is based on the surface velocity difference at elevations of $\sim 4400 \mathrm{~m}$ and $4500 \mathrm{~m}$ measured in autumn and winter by Liu and others (2011). This compressional strain rate is expected to be longitudinal. We further assumed a maximum extensional strain rate $\dot{\varepsilon}_{1}=4 \times 10^{-10} \mathrm{~s}^{-1}$, presumably in the transverse direction, as the magnitude of the maximum extensional strain is expected to be close to $\dot{\varepsilon}_{2}$ from previous glacier strain rate measurements (Meier and others, 1974). The maximum tensional stress for this scenario is the same with the first scenario on the surface, but an increase of $36 \mathrm{kPa}$ at $50 \mathrm{~cm}$ depth in comparison with the first scenario is due to the background tensional strain rate. The background strain rate dominantly controls the stress state at one-meter depth or deeper, as the stress asymptotically approaches $73 \mathrm{kPa}$ in this scenario (Fig. 11f2). The enhanced tensile stress at depth can promote downward propagation of surface cracks and continued seismic events.

In either scenario, our thermal stress calculation clearly shows that the daily variations in the glacier thermal state are prominent only in the top tens of centimeters of the glacier. If the thermal effect dominates, it implies that the night-time short-duration events occur or at least initiate within the top tens of centimeters. In addition, the thermal stress is much lower than the stress threshold of $1 \mathrm{MPa}$ that is required to fracture intact ice (Schulson, 1999 and references therein). Instead, the thermal stress is on the same order of magnitude as the critical tensile stress for crack nucleation and propagation if small pre-existing defects or weak planes exist (van der Veen, 1998).

\section{Comparison with fracture mechanics}

Based on the fracture mechanic considerations, the initiation of seismic events implies the moment when the maximum thermal stress reaches the critical tensile stress for fracture formation. The thermal tensile stress during 19 CST to 9 CST the next day with daily bursts of short-duration events is on the order of tens of kilopascals with a maximum tensile stress of $156 \mathrm{kPa}$ on the surface. The calculated thermal tensile stress is consistent with the fracture models of van der Veen (1998), who suggests a critical tensile stress range of $90-320 \mathrm{kPa}$ for a densely spaced crack system. The nonexistence of a clear $b$-value evolution trend implies that the detected short-duration events at different hours of the day likely occur in a similar strain and stress state (Nishio, 1983; Podolskiy and Walter, 2016). As the state of stress and strain differs notably with depth, the short-duration events may not propagate with depth, but mainly correspond to initiation of new surface cracks.

The uncertainties in our stress calculation are primarily due to the applicability of Glen's flow law and a lack of constraints on creep parameter $C_{*}$ in Glen's flow law. The applicability of Glen's flow law in different temperature and strain rate region is currently under debate (Schulson and Duval, 2009) and requires further strain and stress measurements. For example, Weiss and others (2007) found that instead of viscous deformation, the winter and/or perennial sea ice behaves as an elastic-brittle body. In this scenario, the temperature difference between the surface and bottom of the glacier may induce a thermal bending moment at night (Evans and Untersteiner, 1971; Bažant, 1992; Carmichael and others, 2012), which is later released by microseismic events. For the creep parameter, material properties such as impurities, reduced grain size, increased water content and anisotropic ice fabrics can increase $C_{*}$ by several fold, and the field measurements of $C_{*}$ in different glaciers also commonly varies by a factor of 1-3 (Cuffey and Paterson, 2010 and references therein). Material factors are also suggested 

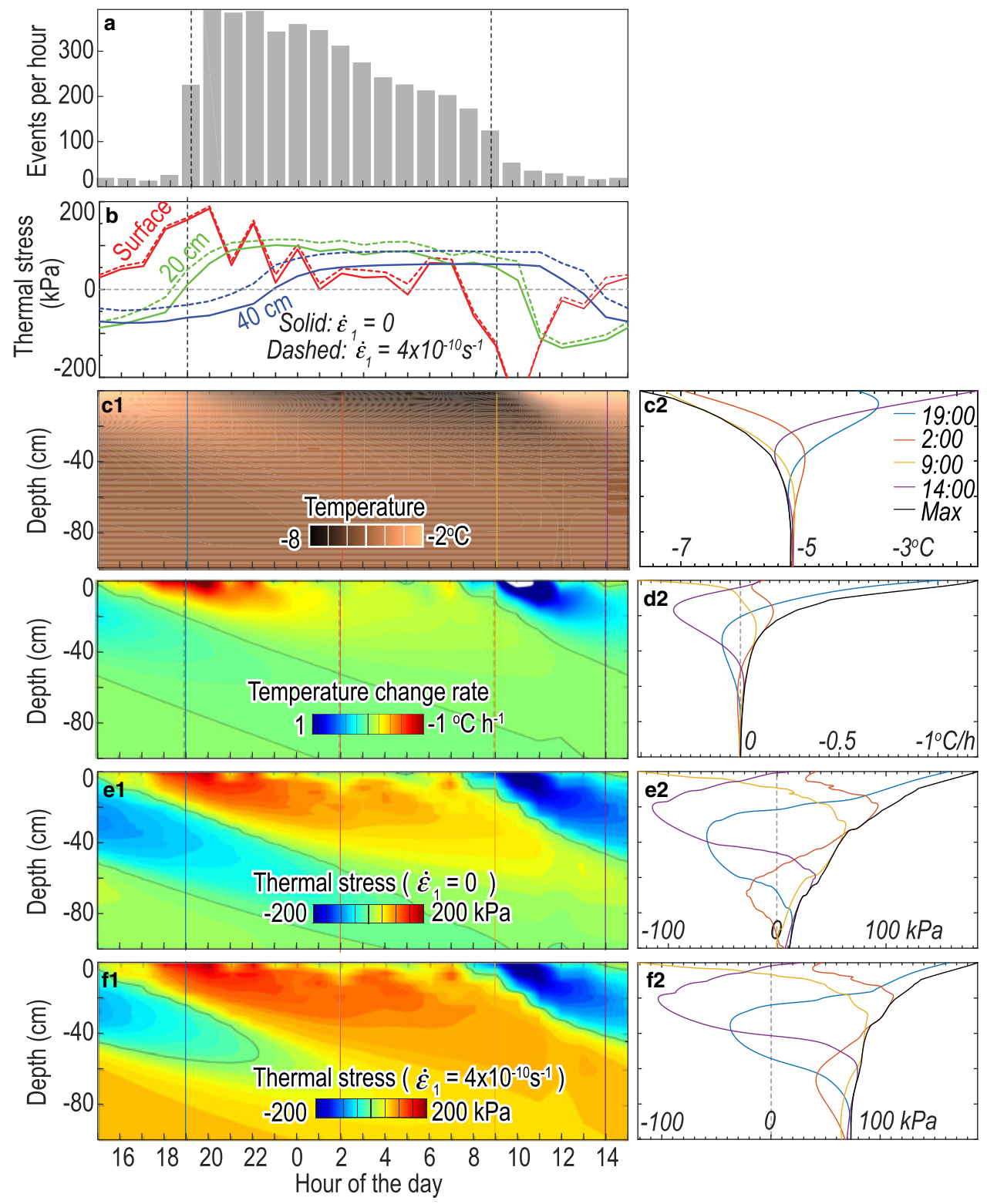

Fig. 11. Hourly short-duration event counts, temperature, temperature change rate and thermal stress averaged for the 9 survey days. (a) Counts of short-duration events per hour (same with Fig. 9c). (b) Calculated thermal stress evolution at a depth of 0 (red), 20 (green) and $40 \mathrm{~cm}$ (blue). The solid and dashed curves correspond to (e1-2) the first scenario without background strain rate and (f1-2) the second scenario with background strain rate, respectively. (c1-2) Temperature wave propagation and corresponding depth-dependent temperature profiles at four representative times. Black curve shows the lower enveloping curve of the temperature at various depths. (d1-2) Depth-dependent evolution of temperature change rate and corresponding temperature change rate profiles. Black curve shows the higher enveloping curve. (e1-2) Calculated thermal stress evolution for the first scenario without background strain rate, and depth-dependent profiles. Black curve shows the upper enveloping curve of the tensile stress at various depths. (f1-2) Calculated thermal stress evolution for the second scenario with a background strain rate. The horizontal tension is positive.

to influence the fracture toughness (Vaughan, 1993; Rist and others, 1996, 1999). Therefore, local field stress and strain measurements are necessary for further calibrating the constitutive relationship and quantitatively understanding icequakes and glacier dynamics.

\section{POSSIBLE SOURCES FOR LONG-DURATION EVENTS}

The tremor-like long-duration events can be produced by subglacial water flow or repeated basal ruptures (Helmstetter and others, 2015; Podolskiy and Walter, 2016). The correlation between ice stream velocity and tremor signal is necessary to associate the tremor with basal ruptures (Winberry and others, 2013). However, there is no variations of glacier displacement correlated with the long-duration events in the coincident position measurements at stations S2 and S3 (Yan Peng, manuscript in preparation). Considering the slow surface velocity $\left(\sim 9 \mathrm{~cm} \mathrm{a}^{-1}\right)$ in the study area (Liu and others, 2011; Wang and others, 2016) and the thinness of the ice (56-128 m), we excluded the mechanism of repeated basal rupture for the long-duration events. Instead, we suggest that our long-duration events are most likely due to subglacial water flow. Firstly, our tremor-like long-duration events emit seismic energy in a dominant frequency of $<20 \mathrm{~Hz}$, which have been attributed to water resonance in fluid-filled moulin (Röösli and others, 2014). Our observed secondary resonance frequency 
of 40 or $80 \mathrm{~Hz}$ is also close to the water resonance frequency of $30-80 \mathrm{~Hz}$ for water-filled fractures (Helmstetter and others, 2015). In addition, more counts of long-duration events are observed at down-glacier stations, where melting is likely to be more prevalent and water flow should be larger. We also found an ice moulin near the seismic station S1 where the largest number of long-duration events were detected. It is thus possible that a large amount of these events are associated with water resonance in the ice moulin. Although we did not directly observe water flow in the moulin or downstream riverbed, surface melting in the daytime may be guided by the near-surface hydrological system into the ice moulin. Finally, the temporal evolution of the resonance frequency (Fig. 5) is also consistent with the water resonance mechanism, as it can be explained by the changes in the fracture width/length or water level (Röösli and others, 2014; Helmstetter and others, 2015). Therefore, we suggest that the most likely source mechanism for the long-duration events is water resonance within the ice moulin.

We cannot exclude the influence of wind as the hourly event counts and wind speed are positively correlated with correlation coefficients of $0.26-0.44$. In addition, the wind speed at 14-18 CST (Fig. 6b) exceeds a critical value of 3 $\mathrm{m} \mathrm{s}^{-1}$ that can induce large seismic noise (Withers and others, 1996). However, the wind noise cannot explain the existence of resonance frequencies at selected frequency ranges (e.g. $80 \mathrm{~Hz}$ in Fig 5a). Although additional seismic measurements within deep boreholes are necessary to elucidate this point, we suggest that wind noise alone cannot explain the all of detected long-duration events.

\section{CONCLUSIONS}

Our observations and analyses of seismic events and temperature fluctuations in LGNT lead to the following conclusions:

(1) We detected long-duration tremor-like events in the daytime and short-duration seismic events in the nighttime at LGNT.

(2) The night-time short-duration events are characterized by relatively short duration, high dominant frequency, large event counts, and dominance of Rayleigh waves, and are thus inferred to be caused by near-surface crack opening. On a daily basis, the occurrence of the short-duration events was negatively correlated with the temperature and temperature change rate. Although we cannot exclude the effect of meltwater refreezing, night-time thermal tensile stress in the top tens of centimeters of the glacier exceeds the critical tensile stress and thus is enough to induce ice fractures and associated seismicity.

(3) The daytime long-duration events are characterized by relatively long duration, low dominant frequency, low event number, and tremor-like waveform. They are likely related to water resonance in an ice moulin filled by daytime meltwater.

\section{ACKNOWLEDGEMENTS}

We thank Qin Xiang at Cold and Arid Regions Environmental and Engineering Research Institute, Chinese Academy of Sciences, Yan Peng at Wuhan university and other colleagues working at Qilian Mountain Station of Glaciology for their support of the seismic experiment. We also thank F. Walter, E. Podolskiy and J. Amundson for their valuable reviews and constructive comments. The project was supported by the National Natural Science Foundation of China (41576065, 41776189, 41806067, 91628301), the Scientific Research Fund of the Second Institute of Oceanography, SOA (QNYC201503), the Chinese Polar Environment Comprehensive Investigation and Assessment Programmes (CHINARE 03-03, 04-03, and 01-03), the Key Laboratory of Ocean and Marginal Sea Geology, Chinese Academy of Sciences (No. OMG18-XX) and the Chinese Academy of Sciences (Y4SL021001).

\section{REFERENCES}

Barruol G and 5 others (2013) Tide-induced microseismicity in the Mertz glacier grounding area, East Antarctica. Geophys. Res. Lett. 40(20), 5412-5416

Bassis JN and 6 others (2007) Seismicity and deformation associated with ice-shelf rift propagation. J. Glaciol. 53(183), 523-536

Bažant ZP (1992) Large-scale thermal bending fracture of sea ice plates. J. Geophys. Res. Oceans 97(C11), 17739-17751 (doi: 10.1029/92JC00816)

Carmichael JD, Pettit EC, Hoffman M, Fountain A and Hallet B (2012) Seismic multiplet response triggered by melt at Blood Falls, Taylor Glacier, Antarctica. J. Geophys. Res. 117(F3), F03004 (doi: 10.1029/2011JF002221å)

Carmichael JD and 6 others (2015) Seismicity on the western Greenland Ice Sheet: surface fracture in the vicinity of active moulins. J. Geophys. Res. 120(6), 1082-1106 (doi: 10.1002/ 2014JF003398)

Cuffey KM and Paterson WSB (2010) The physics of glaciers. Butterworth-Heinemann/Elsevier, Burlington

Dalban Canassy P and 5 others (2013) Investigating the dynamics of an Alpine glacier using probabilistic icequake locations: Triftgletscher, Switzerland. J. Geophys. Res. 118(4), 2003-2018 (doi: 10.1002/jgrf.20097)

Deichmann $\mathrm{N}$ and 5 others (2000) Evidence for deep icequakes in an Alpine glacier. Ann. Glaciol. 31(1), 85-90

Du W, Qin X and Liu Y (2008) Variation of the Laohugou Glacier No. 12 in the Qilian Mountains. J. Glaciol. Geocryo. 30(3), 373-379

Ekström G, Nettles M and Abers GA (2003) Glacial earthquakes. Science 302(5645), 622-624

Evans RJ and Untersteiner N (1971) Thermal cracks in floating ice sheets. J. Geophys. Res. 76(3), 694-703 (doi: 10.1029/ JC076i003p00694)

Glen JW (1955) The creep of polycrystalline ice. Proc. R. Soc. Lond. A. 228(1175), 519-538

Gutenberg B and Richter CF (1944) Frequency of earthquakes in California. Bull. Seis. Soc. Am. 34, 185-188

Helmstetter A, Moreau L, Nicolas B, Comon P and Gay M (2015) Intermediate-depth icequakes and harmonic tremor in an Alpine glacier (Glacier $\mathrm{d}^{\prime}$ Argentière, France): evidence for hydraulic fracturing?. J. Geophys. Res. Earth. 120(3), 402-416 (doi: 10.1002/2014JF003289)

Köhler A, Nuth C, Schweitzer J, Weidle C and Gibbons SJ (2015) Regional passive seismic monitoring reveals dynamic glacier activity on Spitsbergen, Svalbard. Polar Res. 34(1), 26178

Liu Y, Qin X, Du W, Sun W and Hou D (2011) The movement features analysis of Laohugou Glacier No. 12 in Qilian Mountains. Sci. Cold Arid Reg. 3(2), 119-123

Meier MF, Kamb WB, Allen CR and Sharp RP (1974) Flow of blue glacier, Olympic Mountains, Washington, USA. J. Glaciol. 13 (68), 187-212 (doi: 10.1017/S0022143000023029)

Mikesell TD and 5 others (2012) Monitoring glacier surface seismicity in time and space using Rayleigh waves. J. Geophys. Res. Earth. 117, F02020 (doi: 10.1029/2011JF002259) 
Neave K and Savage J (1970) Icequakes on the Athabasca glacier. J. Geophys. Res. 75(8), 1351-1362

Nishio F (1983) Studies on thermally induced fractures and snowquakes of polar snow cover. Mem. Natl. Inst. Polar Res. Ser. C, Earth Sci. 14, 1-48

Osten-Woldenburg HVD (1990) Icequakes on Ekström Ice Shelf near Atka Bay, Antarctica. J. Glaciol. 36, 31-36 (doi: 10.3189/ S0022143000005517)

Podolskiy EA and Walter F (2016) Cryoseismology. Rev. Geophys. 54, 708-758

Podolskiy EA and 7 others (2016) Tide-modulated ice flow variations drive seismicity near the calving front of Bowdoin Glacier, Greenland. Geophys. Res. Lett. 43, 2036-2044 (doi: 10.1002/ 2016GL067743)

Podolskiy EA, Fujita K, Sunako S, Tsushima A and Kayastha RB (2018) Nocturnal thermal fracturing of a Himalayan debriscovered glacier revealed by ambient seismic noise. Geophys. Res. Lett. 45, 9699-9709 (doi: 10.1029/2018GL079653)

Qin X and 5 others (2014) Reconstruction of surface air temperature in a glaciated region in the western Qilian Mountains, Tibetan Plateau, 1957-2013 and its variation characteristics. Quatern. Int. 371, 22-30 (doi: 10.1016/j.quaint.2014.10.067)

Qin X and 5 others (2015) Variations of the alpine precipitation from an ice core record of the Laohugou glacier basin during 19602006 in western Qilian Mountains, China. J. Geogr. Sci. 25(2), 165-176 (doi: 10.1007/s11442-015-1160-4)

Richter CF (1935) An instrumental earthquake magnitude scale. Bull. Seism. Soc. Am. 25(1), 1-32

Richter CF (1958) Elementary seismology. W.H. Freeman, San Francisco

Rist MA and 5 others (1996) Experimental fracture and mechanical properties of Antarctic ice: preliminary results. Ann. Glaciol. 23, 284-292

Rist MA and 6 others (1999) Experimental and theoretical fracture mechanics applied to Antarctic ice fracture and surface crevassing. J. Geophys. Res. 104(B2), 2973-2987

Röösli C and 6 others (2014) Sustained seismic tremors and icequakes detected in the ablation zone of the Greenland ice sheet. J. Glaciol. 60(60), 563

Röthlisberg H (1955) Studies in glacier physics on the Penny Ice Cap, Baffin Island, 1953: Part III: seismic sounding. J. Glaciol. 2, 539-552 (doi: 10.3189/002214355793702064)

Roux PF, Marsan D, Métaxian JP, O’Brien G and Moreau L (2008) Microseismic activity within a serac zone in an alpine glacier (Glacier d'Argentière, Mont Blanc, France). J. Glaciol. 54(184), 157-168

Roux PF, Walter F, Riesen P, Sugiyama S and Funk M (2010) Observation of surface seismic activity changes of an Alpine glacier during a glacier-dammed lake outburst. J. Geophys. Res. 115, F3014 (doi: 10.1029/2009JF001535)

Sanderson T (1978) Thermal stresses near the surface of a glacier. J. Glaciol. 20(83), 257-283

Schulson EM (1999) The structure and mechanical behavior of ice. JOM 51(2), 21-27 (doi: 10.1007/s11837-999-0206-4)

Schulson EM (2002) Brittle failure of ice. Rev. Mineral. Geochem. 51 (1), 201-252 (doi: 10.2138/gsrmg.51.1.201)

Schulson EM and Duval P (2009) Creep and fracture of Ice. Cambridge University Press, Cambridge

Stevenson PR (1976) Microearthquakes at Flathead Lake, Montana: a study using automatic earthquake processing. Bull. Seism. Soc. Am. 66(1), 61-80
Sun W and 5 others (2011) Annual variations of the components of radiation on the Laohugou No. 12 Glacier in the Qilian Mountains. Adv. Earth Sci. 26(3), 347-354

Sun W and 7 others (2013) Characteristics of micrometeorological elements in accumulation zone of Laohugou Glacier No. 12 in Qilian Mountains. Plateau Meteo. 6, 1673-1681 (doi: 10.7522/ j.issn.1000-0534.2012.00157)

Sun W and 9 others (2014) Ablation modeling and surface energy budget in the ablation zone of Laohugou glacier No. 12, western Qilian mountains, China. Ann. Glaciol. 55(66), 111120 (doi: 10.3189/2014AoG66A902)

Trnkoczy A (2012) Understanding and parameter setting of STA/LTA trigger algorithm. In Bormann P ed. New Manual of Seismological Observatory Practice 2 (NMSOP2), GeoForschungsZentrum GFZ, Potsdam, 1-20 (doi: 10.2312/gfz.nmsop-2_is_8.1)

van der Veen CJ (1998) Fracture mechanics approach to penetration of surface crevasses on glaciers. Cold Reg. Sci. Tech. 27(1), 31-47

van der Veen CJ (1999) Crevasses on glaciers. Polar Geogr. 23(3), 213-245

van der Veen CJ (2007) Fracture propagation as means of rapidly transferring surface meltwater to the base of glaciers. Geophys. Res. Lett. 34(1) (doi: 10.1029/2006GL028385)

Vaughan DG (1993) Relating the occurrence of crevasses to surface strain rates. J. Glaciol. 39(132), 255-266

Walter F, Deichmann N and Funk M (2008) Basal icequakes during changing subglacial water pressures beneath Gornergletscher, Switzerland. J. Glaciol. 54(186), 511-521 (doi: 10.3189/ 002214308785837110)

Walter F and 5 others (2009) Moment tensor inversions of icequakes on Gornergletscher, Switzerland. Bull. Seism. Soc. Am. 99(2A), 852-870

Walter F and 5 others (2012) Analysis of low-frequency seismic signals generated during a multiple-iceberg calving event at Jakobshavn Isbræ, Greenland. J. Geophys. Res. 117(F1), F01036 (doi: 10.1029/2011JF002132)

Walter F, Canassy PD, Husen S and Clinton J F (2013) Deep icequakes: what happens at the base of Alpine glaciers?. J. Geophys. Res: Earth Surf. 118(3), 1720-1728

Wang Y and 7 others (2016) Ice depth and glacier-bed characteristics of the Laohugou Glacier No. 12, Qilian Mountains, revealed by ground-penetrating radar. J. Glaciol. Geocryol. 38(1), 28-35 (doi: 10.7522 /j.isnn.1000-0240.2016.0004)

Weiss J, Schulson EM and Stern HL (2007) Sea ice rheology from in-situ, satellite and laboratory observations: fracture and friction. Earth Plane. Sci. Lett. 255(1), 1-8 (doi: 10.1016/j. epsl.2006.11.033)

Winberry JP, Anandakrishnan S and Alley RB (2009) Seismic observations of transient subglacial water-flow beneath MacAyeal Ice Stream, West Antarctica. Geophys. Res. Lett. 36, L11502 (doi: 10.1029/2009GL037730)

Winberry JP, Anandakrishnan S, Wiens DA and Alley RB (2013) Nucleation and seismic tremor associated with the glacial earthquakes of Whillans Ice Stream, Antarctica. Geophys. Res. Lett. 40, 312-315 (doi: 10.1002/grl.50130)

Withers MM, Aster RC, Young CJ and Chael EP (1996) High-frequency analysis of seismic background noise as a function of wind speed and shallow depth. Bull. Seism. Soc. Am. 86(5), 1507-1515

Zoet LK, Anandakrishnan S, Alley RB, Nyblade AA and Wiens DA (2012) Motion of an Antarctic glacier by repeated tidally modulated earthquakes. Nat. Geosci. 5(9), 623 